\title{
Keeping us grounded: academic staff perceptions of service user and carer involvement in health and social work training
}

Joy M. Rooney, Peter F. Unwin and Prag Shah

Institute of Health and Society, University of Worcester, Worcester, UK

Corresponding author. Correspondence should be addressed to Dr. Joy M. Rooney at Institute of Health and Society, University of Worcester, Henwick Grove, Worcester, WR2 6AJ. Email: j.rooney@worc.ac.uk Telephone: 07918603049

Dr. Joy M. Rooney is an Associate Lecturer and IMPACT service user and carer group member in the Institute of Health and Society at the University of Worcester. Dr. Peter Unwin is a Principal Lecturer in Social Work at the University of Worcester and facilitator of the University's IMPACT service user and carer group. Prag Shah is an Associate Lecturer and IMPACT service user and carer group member in the Institute of Health and Society at the University of Worcester. 


\title{
Keeping us grounded: academic staff perceptions of service user and carer involvement in health and social work training
}

\author{
Academic staff perceptions of the value and purpose of service user and carer \\ (SUAC) involvement within a health and social work faculty in an English \\ university were explored in this co-produced qualitative study. Relevant \\ research findings over the past two decades were reviewed and two SUAC \\ researchers, plus an academic member of staff, designed the study based around \\ fifteen semi-structured telephone interviews.
}

Findings were that staff were very positive about the benefits brought by SUAC involvement, in respect of their own grounding, knowledge, and continuing professional development (CPD), these findings not having previously been reflected in the literature. Barriers to involvement of SUACs were found to be negligible compared to those found in recent literature, and the input of SUACs appeared to be embraced by academic staff. This changing picture has emerged at a time when managerialism and marketization affect the working conditions of staff. In times of increasing workloads, this study suggested that academics find SUAC involvement both supportive and constructively challenging. SUACs were perceived to bring fresh interdisciplinary knowledge and challenges to staff value bases alongside constructs of professionalism that staff may not be able to access elsewhere. The encouragement of interdisciplinary ways of thinking was noted to have been a serendipitous consequence of SUACs from different backgrounds inputting on courses across the faculty.

Recommendations are to better ensure consistency in the use of SUACs in terms of resourcing, support, and development if such involvement is to be meaningful rather than marginalised and de-valued.

Keywords: staff views, health and social work, service users and carers, higher education, disadvantages and barriers to involvement, co-production

\section{Introduction}

For more than a decade the University of Worcester, England, has included SUACs in the recruitment and education of its students, its SUAC group being known as 
'IMPACT'. In England, the use of SUACs in academic settings is encouraged by legislation and policy, particularly after recent concerns regarding standards in practice, such as those evidenced in the Francis Report (Francis, 2013), where the voices of service users and carers had not been heard by professionals and their managers. SUACs come from a variety of backgrounds - care leavers, carers, disabled people, survivors of domestic violence, people with learning disabilities and people with mental health and substance abusing issues. Most universities recruit locally through word of mouth and SUACs will usually be paid expenses plus a fee for their engagement with university teaching, recruitment and research or for involvement in quality initiatives, such as course development and review. SUAC involvement within policy was first identified in the National Health Service and Community Care Act (1990) where a model of consumerism was promoted in an emerging patient-led NHS. SUAC involvement in qualifying social work training was made mandatory by the Department of Health (2002) and has been part of qualifying nurse training since 1996. The Department of Health (2006) made recommendations for higher education institutions (HEIs) to include SUACs across all nursing activities to enable best practice. Glasby and Beresford (2006) promoted SUAC involvement, specifically in the research arena, as a necessary antidote to the elitist hierarchy that has characterised Western academia. Such a view positions SUAC knowledge as a different kind of knowledge, rather than an inferior type of knowledge, to that held by senior academics and professionals.

Part of New Labour's marketisation and modernisation agenda for the NHS was designed to enable more choice for service users, with a focus on identifying and including SUAC in the delivery and service design of their own care packages (Stacey, Stickley and Rush, 2012). Similar policies of modernisation and marketisation have also come to dominate Higher Education (HE) in England (Naidoo, Shankar and Veer, 
2011) where staff workloads have increased significantly (Graham, 2015). This consumerist agenda can be critiqued as an anti-professional neo-liberal stance which views health and social work services as businesses in which the customer is king (Harris, 2003).

This study was designed as a contemporary critique of staff perceptions of the value of SUAC involvement in the current climate of HE.

\section{Literature Review}

There is an increasing evidence base regarding academic staff views of SUAC involvement in HE, mostly made up of small scale qualitative studies. Most of the early literature can be viewed as positive in its perspectives on SUAC involvement, which is variously seen as humanising the classroom, bringing about a greater valuing of lived experience and developing enhanced skills and confidence in the SUAC participants (Masters et al., 2002; Felton and Stickley, 2004; McGarry and Thom, 2004). The General Social Care Council (2005) used a mixed methods approach in exploring participation across HEIs via analysis of annual monitoring forms, regional inspections, external examination reports, university publications and questionnaires to SUAC organisations and individuals $(\mathrm{n}=44)$. Findings were that HEI staff perceived all stakeholder groups (students, staff and SUACs) to have benefited from SUAC involvement. Cooper and Spencer-Dawe (2006) used a focus group of interprofessional health educators $(n=7)$ to conclude that the co-facilitation of interprofessional workshops with service users enabled students to narrow the gap between theory and practice. This positive vein of research continued with a qualitative study by Simons et al. (2007) which involved staff $(n=10)$ from pre-qualifying and postqualifying mental health nursing courses and found that the involvement of SUACs in 
the design of curriculum was beneficial because of the powerful, positive role model this provided for students. One of the first studies regarding the involvement of SUACs in selection processes was carried out by Vandrevala et al. (2007) who concluded that the involvement of SUACs in recruiting post-graduate mental health clinical psychologists led to high calibre candidates being selected. This finding was perceived as having been brought about via candidates demonstrating good communication skills and greater levels of awareness about SUAC perspectives. Anghel and Ramon (2009) undertook the first study of SUAC involvement in social work training and found that lecturers ( $n=24)$ were positive in respect of offering students a more humanistic, fresher perspective than the academic one, and also challenged stereotypes of SUACs.

Simons, Tee and Coldham (2010) studied the views of mental health nurse academics $(n=33)$ regarding the design and delivery of curriculum by SUACs, and identified that SUACs were perceived as valuable learning resources, whose presence modelled the principles of value-based practice. Holttum and Hayward (2010) found mental health clinical psychology staff $(n=81)$ across two HEIs perceived that decision making in respect of student and staff selection, involvement in teaching, research and course administration were all significantly improved when SUACs were involved.

The complexities inherent in including SUACs in territory previously viewed as the exclusive domain of academics has begun to be acknowledged in some of the more recent literature. Ion, Cowan and Lindsay (2010), for example, brought a more reflective perspective on staff views regarding the involvement of SUACs in module design and delivery and suggested all parties needed to be prepared to work together in an honest and open way. Their following quote perhaps encapsulates the challenging nature of this area of involvement for all concerned: 
Arrangements for working together should be based on mutual respect. The starting point for this should be an acceptance and valuing of difference and diversity and a simple commitment to ensure that service user colleagues are appropriately rewarded for their work. Educationalists should take the time to help prepare students and service user lecturers for service user led teaching sessions. Academic staff should also be willing to provide constructive peerbased feedback on service user performance, and service users should be prepared to hear this and work with it. All parties should be aware that meaningful involvement may be personally challenging and can also be both time consuming and difficult

(Ion, Cowan and Lindsay, 2010: 9).

The complexities noted above were also commented upon by Matka et al. (2010), whose survey of lecturers involved in recruiting students for social work and clinical psychology courses, suggested that most lecturers benefitted from the reality check brought to such processes by SUAC involvement. Further challenges to academics were noted by Fraser (2015), in a study of SUACs' involvement in occupational therapy courses, the main challenges being related to the dual professionalism of being a therapist and a lecturer, and having to be clear about these respective roles when working with SUACs. This study is also notable in that it reported higher student satisfaction scores in module evaluations, attributable to SUAC involvement. Finally, Lea et al. (2016) carried out a small-scale qualitative study on the views of SUACs, students and clinical psychology lecturers regarding the impact of SUAC involvement in curriculum design and delivery, and found that the lecturers 
reported positive outcomes in terms of encouraging them to value lived experience more. Such findings as these above can be seen to resonate with much of the earlier, positive literature.

The literature across the past two decades also shows consistencies in its expressions of reservations and difficulties in respect of HE embracing the SUAC contribution. Issues such as lack of organisational support, criticism of SUAC groups' representativeness and general difficulties in achieving balance between tokenism and meaningful involvement are ever-present themes. Reaching an appropriate balance between tokenism and the fullest possible involvement seem to depend on a range of factors from the attitudes of academic staff through to institutional support. Attitudinal barriers were less in evidence than organisational ones, McGarry and Thom’s (2004) small-scale qualitative study with mental health nursing lecturers having reported a fearfulness that SUAC might use the classroom to vent their frustrations, whereas O’Keefe and Jones (2007) reported that faculty participants ( $n=10)$ from an Australian university presumed ownership of curriculum development. This latter study reported a paternalistic approach toward controlling resources and an assumed responsibility (as the 'real' experts) to define the parameters of lay participation. Gutteridge and Dobbins (2009) interviewed health academics and administrators ( $n=20)$, in an English university regarding perceptions of SUAC impact on student learning, and found that staff, despite having been generally positive about SUAC involvement, believed attitudinal barriers continued to exist in respect of leadership and direction, alongside organisational boundaries regarding payments, induction, support and training. This study, supported later by Skilton (2011), also expounded the view that SUACs sometimes had unrealistic expectations of students, a problem which could be rectified by the provision of appropriate preparation and induction, as identified throughout the 
literature (Masters et al., 2002; McGarry and Thom, 2004; Anghel and Ramon, 2009). Molyneaux and Irvine (2004), using a postal questionnaire to post-qualifying course social work staff in 19 HEIs, found at least six organisations expressed difficulties in reaching a balance between tokenism and meaningful involvement of service users and carers, citing particular difficulties with organisational arrangements and noting that there was no one formula for success. Baldwin and Sadd (2006) expressed concerns regarding unhelpful power dynamics between an external SUAC group and the setting up of a SUAC involvement group at an English university, partly due to resource limitations. Taylor et al. (2006) found HEI staff $(n=100)$ reported some difficulties with SUAC involvement in social work partnership learning and teaching, particularly related to the need for a value-based commitment to partnership that included wider institutional support. Rhodes and Nyawata’s (2011) study of academics' views ( $\mathrm{n}=5)$ regarding SUACs' involvement in the selection of health and social care students also stressed the importance of proper resourcing. This study, although small in scale, was notable for its identification of concern and uncertainties regarding balance of power issues. Speed et al. (2012) carried out a study of nursing and midwifery staff and lecturers $(n=23)$ which continued to echo previous studies in its identification of potential barriers to SUAC involvement. These themes were:

(1) SUACs not being made aware of the context of the student group

(2) Lack of SUACs preparation by academic staff

(3) Lack of support

(4) Not being allowed to be real

(5) Not receiving feedback

(6) Not being paid appropriately. 
Burrows (2012) in a study of post-qualifying social work identified further barriers in respect of a lack of staff time, and recommended that the voices of 'rarely heard' marginalised SUACs were also included at HEIs. Webber and Robinson (2012) studied the views of a range of post-qualifying social work programme stakeholders $(n=7)$ and uncovered a divide between those who believed that the key importance of SUACs involvement was to capture knowledge and perspectives which added value to programmes, and those who believed that the primary purpose of SUAC involvement was to facilitate the personal development of the SUACs involved, and to challenge the power imbalance between professionals and SUACs. One programme leader valued having a user consultant as a member of the programme team, while another championed the developmental benefits of having two or three people involved over a long period. Long-term involvement enabled them to gain respect as co-workers in the university department and a full understanding of the programme, which enhanced the quality of their contribution. It also allowed them to make a rich and meaningful contribution to all aspects of the programme, encompassing the design of modules, recruiting students, teaching and assessment, reviewing and evaluation of the programme. Mackey and Millar (2012) carried out a study of the involvement of young people and adult SUACs in the classroom with social work students and echoed the recommendations of previous studies (for example, Rhodes and Nyawata, 2011; Speed et al., 2012) in their findings regarding the need to avoid tokenism, and to ensure a sound organisational commitment to providing effective support, enabling structures and processes.

Happell et al. (2015) chose a telephone interview methodology with nurse academics from 27 Australian universities involved in SUAC input into pre-registration and postgraduate mental health nurse training. The three themes to emerge from this 
large-scale study in regard to lived experience in teaching mental health nursing around recovery were those of:

(1) Helping students face fear of mental ill health - for example, the fear of being physically hurt on acute wards

(2) Demystifying mental illness - seeing people with mental health diagnoses in non-judgemental ways

(3) Barriers of power and the 'practitioner-knows-best' philosophy that academic staff believed still prevailed in Australian universities.

The above reservations and difficulties must be weighed against the volume of research which sees only positives in SUAC inclusion at HEIs, and it might be argued that many of these barriers could be easily overcome with greater organisational support, the resourcing of such involvement being minor in the scale of HEI budgets. The growth of literature regarding academic staff views of SUAC involvement over the past two decades years can be seen to have consolidated in some areas, notably those of SUACs bringing a richness of experience to the classroom, which is further guaranteed when appropriate resources and organisational support are provided. Questions remain, however, about quite what the role of SUACs in HE should be, particularly in the modern marketised workplace with its the pressures of time and resources, which may mean that there is no time for fuller consideration regarding power imbalances, addressing the representativeness of SUACs involved in HEIs and the need for induction and preparation for this exacting role-set. This study was intended to further refine and explore such issues based on the perceptions of staff from social work, nursing and related courses in an English university. 


\section{Methodology}

Ethical approval for the research project was granted by the Ethics Committee of the Institute of Health and Society at the University of Worcester. Contact was made by email to 25 academics who regularly work with IMPACT, the University of Worcester's in-house SUAC group. Fifteen academics (3 men and 12 women) agreed to participate, these participants having worked at the university for between 18 months and 12 years. Specialisms ranged across undergraduate and post-graduate courses and included health foundation degree courses, mental health nursing, nursing, midwifery, occupational therapy, physiotherapy, and social work. It was communicated that participants would not be identifiable in the research findings as their specific discipline would not be referred to, or be identifiable, in any way. The university is committed to the principles of co-production (Bovaird, 2007) and endeavours to model a sharing of power in terms of the holistic nature of any research project from design through to publication. The research idea arose from a meeting of the IMPACT group, and its operationalisation involved semi-structured Skyped telephone interviews, undertaken by two IMPACT peer researchers, with the academic staff member being involved in the study design, analysis and write-up. Participants were asked to choose the time of interview to allow for maximum convenience and privacy. Semi-structured interview questioning was around:

(1) The contribution made by SUACs to the work of academics

(2) Perceived quality of SUAC involvement

(3) Perceived effects of SUAC involvement on student learning

(4) Perceived wider benefits to students from SUAC involvement

(5) Perceived disadvantages of working with SUACs, either to staff or students

(6) Barriers and challenges to working with SUACs

(7) Effect on self from working with SUACs 
(8) Ideas for improvement/ expansion of SUAC involvement

(9) Perceived benefits to SUACs

(10) Any further comments.

The resulting Skype recordings were transcribed verbatim and produced a very large volume of qualitative data, a thematic analysis approach (Braun and Clarke, 2006) being adopted to manage such volume. This approach is concerned with identifying all data that seems to exemplify the same issue with the same code, and demands the reading and re-reading of data until points of saturation are reached via techniques of summarising, linking and redefining themes in the search for analysis and interpretation (Gibbs, 2007). Transcripts were made available to each research team member, who independently read them as part of an interpretive process whereby the analysis was theorised via a process of familiarisation, generation of initial codes, identification of themes, construction of thematic networks and the final stage of integration and interpretation (Robson, 2011). This process led to the emergence of nine key themes:

(1) The contribution made by SUACs to the work of academics;

(2) Perceived quality of SUACs' involvement;

(3) Perceived effects of SUAC involvement on student learning;

(4) Perceived wider benefits from SUAC involvement to students;

(5) Perceived disadvantages of working with SUAC either to staff or students;

(6) Barriers and challenges to working with SUACs;

(7) Effect on self from working with SUACs;

(8) Ideas for improvement / expansion of using SUACs and

(9) Perceived benefits to SUACs.

These above themes are expanded upon in the following section. 


\section{Key Findings}

Participants reported a range of involvement with SUACs as part of their job roles student selection (9), staff selection (3), teaching (9), assessment (5), research (3), curriculum design (1), quality assurance (1) and preparation for practice (1).

\section{The contribution made by SUACs to the work of academics}

The themes here included the importance of personal accounts and lived experience staff appreciated they were dealing with open human beings who showed compassion and humour:

...a compassionate voice of someone who lets them know that nurses are busy; they understand this but still need to be listened to. It helps to focus the student nurses on the reality of issues in the healthcare system (Participant 4).

They also bring with them good communication skills, engagement skills, observation skills, assessment of students in that, and humour. They bring humour with them as well, which is great (Participant 3).

SUACs were perceived to bridge the gap between 'drier' academic teaching and student learning as a resource for student learning:

They give a rich dimension that theory alone certainly can’t provide (Participant 5).

...we equally value service user input as much as we value our own (Participant 13).

SUACs were seen to bring contemporary knowledge and insight which is fresh:

... [bringing] contemporary insight into the needs and perspective of service users (Participant 7).

...also bringing new ideas and fresh ideas to use to the team (Participant 11).

The perception that lecturers can give students all the information apart from the real voice of the patient is captured in the following statement:

We can tell them what the research says, we can tell them about our experiences as staff, but the most important people in all of this are the services users that we're there to serve 
really, and there to treat and do our best for. So I think it's a really important part that we can't, as academics, really capture (Participant 14).

\section{Perceived quality of SUAC involvement}

There was a varied response from participants across the specialisms. SUAC involvement was rated very highly by most staff (6) and variable (4) by those who answered this question. In addition, two participants responded by saying that SUACs gave perspective, one stating that personalised experiences were important as learning tools and another having felt that SUACs provided quality control:

I think it’s dependent on how well briefed and supported by the lecturer the service user or carer feels. But overall, I have never had any experiences of any poor quality (Participant 1).

...their ability to convey the authenticity of their experiences (Participant 8).

...they're positive and inspirational in term of what they can add. Participant 10

It's important that the students have a variable experience because that sort of reflects the reality of using real people ... (Participant 13).

\section{Perceived effects of SUAC involvement on student learning}

Comments were all positive with ‘insider’ views being acknowledged as;

...stretching, developing and challenging student perspectives (Participants 1 and 3).

One participant reported the service user did "better" than they could have:

The service user we had there was so insightful, so articulate with the students as well when we were doing the film, the initial film screenings, getting the students to really engage in the process, which I think they achieved that far better than we could do really (Participant 10). This same participant went on to suggest that involving SUACs assisted in modelling professional behaviours to students, i.e. the way the lecturer spoke to, and generally modelled respectful behaviour to their SUACs as colleagues: 
...as a staff member, you're teaching with a service user, you're modelling a partnership that I think is really important for health professionals to understand... If you're teaching in that way, you're role modelling the respect and the partnership and the collaboration that you're wanting students to understand (Participant 10).

A further modelling viewpoint was expressed as follows:

One is the actual content of what experts' life experiences can bring, but also what's really important is it shows students that we don't just say we have service user involvement, we show that we have it (Participant 13).

Another participant reported that SUAC involvement was the most highly rated part of the curriculum by students and it made them think quite differently:

...they're involved in the in the communication module, that was the most highly evaluated part of the module... students developed their active listening skills (Participant 12).

\section{Perceived wider benefits to students from SUAC involvement}

There was a wide range of ideas expressed (26) regarding the perceived wider benefits to students, ranging from them getting enthused about SUAC issues and going out to do voluntary work, through to creating community change via sharing teaching and research, and becoming more critical in their analysis of theory and policy:

...some [students] are fired to go and get involved in voluntary organisations outside of the university. And I think that's been really important actually that they’ve kind of become, or having heard what that person has to say, they’ve become very passionate about that particular issue. And I know certainly for a couple of people in the group they shared with me that it's meant that they'd gone and become a 'Dementia Friend', for example, or they've got involved in voluntary spaces in other services outside of their teaching programme (Participant 2).

... [students] would have met and heard an inspiring service user story when they're at university and would carry that with them into placement... how to talk to someone about their psychotic experience, for example, and not be afraid (Participant 1). 
Yes, I think the potential to develop new understandings through shared teaching and research, which can then be taken back to create community change (Participant 7).

...become more questioning and generally in a sort of academic theoretical more critical of ideas... (Participant 8).

\section{Perceived disadvantages of working with SUACs, either to staff or students}

Four participants reported there were no disadvantages. However, there was some disquiet expressed regarding of the level of control an academic had over a lesson, not knowing what a SUAC might say. Not being sufficiently aware of SUAC expectations with regards to a class or selection process were also expressed as disadvantages. This would be more the case when insufficient time is made available for planning and preparation with the SUAC about the topic or task at hand:

.....when the purpose [of the session] is clearly explained, and agreed, there are none (Participant 4).

Adequate preparation with the SUAC representative was also seen as a way of lessening the amount of 'mopping up' if a session had been particularly emotional or emotive:

it's a bit anxiety provoking inviting people into a room when you don't know what they're going to say.... and said some quite controversial and quite difficult things that need a bit of mopping up afterwards (Participant 8).

Two participants reported that SUACs made sessions too complex, for example:

I think these were two sessions that were kind of, ended up being somewhat over the student's heads. There were some concepts and issues being discussed that they were quite complex for students at the level of education that they were at (Participant 1).

The negative comments above can all be seen to relate to core issues around the need for preparation, support and development of SUACs. 


\section{Barriers and challenges to working with SUACs}

Twelve participants cited barriers and challenges, including issues which were institutional, organisational and personal whereas three academics said there were no barriers or challenges. The institutional barriers cited workload, bureaucracy, not being able to book a SUAC via the university website, and the fit of lived experience with certain learning outcomes of a module:

....it's time management in terms of giving enough notice and planning sessions in adequate time, because sometimes our workload and the schedule means that we're doing things kind of last minute really (Participant 13).

...it's another thing to organise and do in a busy workload where you're desperately trying to plan your teaching (Participant 10).

If you had a website with your skills on we could just click and book you that would be great (Participant 4).

Organisational barriers included finding the time and energy to include SUACs; availability of SUACs, sometimes at short notice; the need to dig into SUACs' CVs to find a relevant SUAC and the need for a wide range of SUACs if specific illnesses or experiences are sought by staff.

Personal barriers included some SUACs being perceived as poor communicators in classroom settings or that SUACs fall ill and were sometimes not able to deliver, despite a 'reserve' being available through the current booking system:

A long-term condition means you will become sick on a regular basis for longer periods. So, it’s an expected event for me (Participant 4).

Other comments related to the need for time to develop relationships and to understand the IMPACT system of working. Academics did not always receive their first choice of SUAC due to personal circumstances and they did not like this, some preferring to work with IMPACT members they already knew. 


\section{Effect on self from working with SUACs}

Academics gave candid views (26) regarding the effect on themselves brought about from working with SUACs which ranged from finding it "rewarding and quite enriching”, “challenging”, and bringing "normalisation” through to "reframing the way I do things”, and “critically reflecting on my own practice in relation to SUAC feedback" and "thinking about situations differently". The following quotes illustrate the extent to which some staff have experienced challenges to their own value base and how working with SUACs has also helped their professional development:

I've learnt about my own prejudices and wish to control and hold onto power. So, I've been personally challenged by it, which I think has been really good for me as a practitioner and researcher (Participant 1).

I’m challenged really in term of my own teaching and development (Participant 2).

...challenge[d] my own assumptions and prejudices and think about service users as real people rather than people to be done to....rethinking the limits of my professional role. (Participant 8).

Some participants expressed the view that working with SUACs whose lived experience had been chiefly with a different discipline to theirs, was a way of encouraging inter-disciplinary thinking. This broadening of student and staff horizons was particularly commented upon by mental health and adult pre-registration nursing staff:

Many [IMPACT members] have experienced social work backgrounds, and I think that is a real benefit to us in nursing to have that perspective, looking at social care from a wider perspective (Participant 11).

An important key finding was that SUAC involvement was perceived as keeping academic staff grounded: 
I have to kind of remember what we're there for. So, it grounds me back to what do we do this for, if that makes sense... (Participant 12).

I think it just keeps you very grounded...So I think we need to remember that's basically why we're here to help service users when they need us (Participant 14).

...keeping in touch with what's out there (Participant 5).

...reframing the way I do things... (Participant 6).

...critical reflection on your own practice... (Participant 10).

....as indeed, I've used my work with SUAC to enhance my own CV. (Participant 1).

\section{Ideas for improvement / expansion of SUAC involvement}

Participants mentioned 17 ideas for the possible improvement / expansion of SUAC involvement. These included a wider involvement in the evaluation process of selection across the Institute of Heath and Society - updating lists of experts of SUACs more regularly and making such lists available on the university website; SUACs being encouraged to join an academic staff think-tank; being involved in skills simulation and recruiting more SUAC members with experience of dementia and children’s services, these latter areas representing 'rarely heard' voices (Burrows, 2012).

\section{Perceived benefits to SUACs}

Participants identified 26 perceived benefits to SUACs through involvement, which included partnership working, giving something back, doing work which was positive and affirming, emotionally validating lived experience, being viewed as an expert with something to say and helping change the systems at this HEI.

Some academics also recognised that SUACs could use their work at the university to further their own career potential in flexible, social and enjoyable ways:

...give SUACs a purpose in a relatively flexible job (Participant 9).

....improves confidence, a second career, have a passion for education (Participant 10). 
...feel part of a team and contribute to the learning experience (Participant 11).

...they say, absolutely - "I really value and enjoy doing this" (Participant 13).

\section{Any further comments}

Academics generally felt that SUACs were valued team members who kept them grounded and provided them with a better understanding of issues within disciplines across the faculty. SUACs reminded them of their core values and original vocational motivations and were not only seen in terms of helping hands regarding workload. Sharing student feedback from all sessions with SUACs was recommended by five participants as a helpful way of developing SUAC confidence and classroom skills.

\section{Discussion}

The extent and range of SUAC involvement at the University of Worcester follows government policy (Department of Health, 2002; 2006) and is perceived by academics to be embedded in the Institute of Health and Society in terms of selection, teaching and learning, research, curriculum design and quality assurance. SUAC involvement would seem to bring with it a contemporary insider epistemology together with axiological perspectives regarding the humanising effect of such involvement, which can counter the managerial imperatives (Harris and Unwin, 2009) of the contemporary workplace. Staff generally perceived that the type of knowledge passed onto students by SUACs was a different type of knowledge to that of academics (Glasby and Beresford, 2006) and that this knowledge should be equally valued alongside academic knowledge. Limitations of this study were that it was small in scale and took place at a single English university and hence may not be representative of all universities where health and social work qualifying courses are taught. The deployment of a research team made 
up of two IMPACT members and one academic made for a co-produced output, enhanced by individual team member analysis of data prior to agreements being reached regarding key themes. The credibility of this study was further enhanced by the range of staff participants across health and social work disciplines who took part, although the specific discipline of individual respondents was not identified in the findings due to the need to ensure confidentiality. There was an element of bias in that some staff respondents will have been known to the IMPACT researchers, although the candid nature of responses suggested that this was not an inhibitive factor. It is accepted also that, given the focus of this study on staff views, the direct perspectives of SUAC are not represented. This means, for example, that the content under findings such as 'Ideas for improvement lexpansion of involving SUACs', reflected staff and organisational perspectives only. Earlier suggestions by SUACs regarding how to expand and improve involvement can be found in Rooney, Unwin and Osborne (2016).

The findings of Ion, Cowan and Lindsay (2010) regarding the need for mutual respect and the valuing of difference are echoed throughout this study, as is the need to adequately prepare and develop SUAC colleagues (Anghel and Ramon, 2009; Mackey and Millar, 2012) if SUAC involvement is to be meaningful. Findings also suggest that academics might usefully spend more time in planning and preparation, utilising SUACs in this process so that inequalities of power dynamics, cited as barriers by previous commentators (Masters et al., 2002; Felton and Stickley, 2004; Baldwin and Sadd, 2006; Rhodes and Nyawata, 2011), are reduced and planning is not entirely staffbased. Perceptions from staff in earlier studies regarding the difficulty in reaching a balance between tokenism and meaningful SUAC involvement (Molyneaux and Irvine, 2004; Taylor et al., 2006) were not supported in the present study, where strong organisational support and positive staff attitudes emerged. Speed et al.'s (2012) 
reservation regarding the barriers presented by lack of preparation of the student group are, however, partly present, one academic having spoken about the need for 'moppingup’ after a SUAC was involved in teaching and learning, the class in question not having been prepared for the level of emotion expressed. Overall, however, barriers to involvement, although perceived as still being present were less marked than when they were reported in earlier literature (for example, Gutteridge and Dobbins, 2009; Speed et al., 2012). Fraser (2015) suggested that the level of engagement from the students and student satisfaction scores in module evaluation increased when SUACs were involved, such a finding being supported by this study. That students see SUACs who participate in HE activities as role models (Simons et al., 2007) was also demonstrated in this study and there was also agreement that SUACs provide a 'reality-check' (Matka et al., 2010; Happell et al., 2015) for academic staff, in that their work alongside SUACs informs them of contemporary realities regarding individuals' interactions with health and social work systems. Such a reality check is perhaps particularly important at a time when HE is increasingly dominated by managerialism and marketization priorities, which can lead to a loss of focus on ethical and humanistic considerations (Naidoo, Shankar and Veer, 2011).

Overall, this study’s predominantly positive perceptions of staff regarding the value of SUAC involvement in HEIs resonates with the bulk of extant literature over the past two decades (for example, McGarry and Thom, 2004; Cooper and Spencer-Dawe, 2006; Anghel and Ramon, 2009; Holttum and Hayward 2010; Skilton, 2011; Unwin, Rooney and Cole 2017). Additionally, the perceptions of academics in this study provided new knowledge around personal benefits derived from SUAC involvement in terms of helping keep them grounded and contemporary, aware of developments across health and social work disciplines and helping with their own CPD. This study did not 
find that academics perceived SUACs to be primarily involved for their own personal development (Webber and Robinson, 2012), although the benefits to SUACs from HE involvement were seen as significant, as recognised by Rooney, Unwin and Osborne (2016). More significantly, staff perceived that SUAC involvement added value and knowledge to student experiences, while simultaneously enriching the working lives of academics, particularly in respect of challenges presented to value bases and to traditional models of power and knowledge hierarchies (Lea et al., 2016). Furthermore, staff cited how working alongside SUACs had acted as a form of CPD, particularly when workload pressures (Graham, 2015) preclude staff taking up more formal CPD opportunities. A novel finding within this study was the acknowledgement by academic staff that the lived experiences of SUACs brought interdisciplinary perspectives which enhanced staff's own understanding across a range of health and social work issues.

The humanising effects of SUAC involvement on academics found in this study also resonate with those of Lea et al. (2016) and underline the grounding effect of such work as being very important in reminding them of the core value base of their respective professions and the need to be constantly aware of issues of professional power. Findings such as these represent new positive knowledge regarding the SUAC contribution at $\mathrm{HE}$ and might be seen as part of a positive trajectory over the past two decades of activity and research in this area. Voices of the 'rarely-heard' (Burrows, 2012) are part of IMPACT, and academics seemed to find a source of support and knowledge from engagement in work with SUACs who are in everyday touch with contemporary services across health and social work. This is important as a counterbalance for staff and students alike in an increasingly marketised and performancemanaged world where the unique contributions of SUACs can be so easily marginalised and de-valued. However, it can also be argued that, given the consistency of findings in 
all the literature regarding the need to properly resource, support and be clear about the boundary / power issues around SUAC involvement, HEIs should all now be ensuring that these issues are addressed consistently and comprehensively. The evidence base, supported by this study, is clear about the value-added nature that such involvement brings to staff and students alike, while also exemplifying HEIs working inclusively with local communities.

\section{Recommendations}

Recommendations are presented below for possible adoption on a wider scale to best assure meaningful involvement of SUACs within HE in ways that enhance the working experiences of both SUACs and academic staff:

(1) That the knowledge contribution of SUACs within HE should be recognised as bringing with it an important value and educational base that can both develop and ground staff

(2) HEIs need to address the issue of resourcing staff sufficiently to enable appropriate support and development for SUACs

(3) Academics need to be pro-active in their use of existing systems for facilitating and developing SUAC input into their professional worlds, beginning with induction systems.

(4) Academics must always prepare SUACs and students for sessions and debrief as appropriate. 


\section{References}

Anghel, R., and S. Ramon. 2009. “Service Users and Carers’ Involvement in Social Work Education: Lessons from an English Case Study.” European Journal of Social Work 12 (2): 185-199. http://dx.doi.org/10.1080/13691450802567416

Baldwin, M., and J. Sadd. 2006. “Allies with Attitude: Service User, Academics and Social Service Agency Staff Learning How to Share Power in Running Social Work Education Courses.” Social Work Education 25 (4): 348 - 359. http://dx.doi.org/10.1080/02615470600593543.

Bovaird, T. 2007. "Beyond Engagement and Participation - User and Community CoProduction of Public Services." Public Administration Review 67 (5): 846-860. http://dx.doi.org/10.1111/j.1540-6210.2007.00773

Braun, V., and V. Clarke. 2006. “Using Thematic Analysis in Psychology.” Qualitative Research in Psychology 3(2): 77-101. http://www.tandfonline.com/doi/abs/10.1191/1478088706qp063oa

Burrows, H. M. 2012. "Evaluation of the Involvement of Service Users in PostQualifying Social Work Education: Expected and Unexpected Results.” Social Work and Social Science Review 15: 44-56. http://dx.doi.org/10.1921/095352212X655339.

Cooper, H., and E. Spencer-Dawe. 2006. “Involving Service Users in Interprofessional Education: Narrowing the Gap between Theory and Practice.” Journal of Interprofessional Care 20 (6): 603-617. http://dx.doi.org/10.1080/13561820601029767.

Department of Health. 2002. Requirements for Social Work Training. London: The Stationery Office.

Department of Health. 2006. From values to action: The Chief Nursing Officer's review of mental health nursing 
http://webarchive.nationalarchives.gov.uk/20060424185247/http://dh.gov.uk/pro d_consum_dh/idcplg?IdcService.GET_FILEanddID.4368andRendition.Web

Felton, A., and T. Stickley. 2004. "Pedagogy, Power and Service User Involvement.” Journal of Psychiatric and Mental Health Nursing 11 (1): 89-98. http://dx.doi.org/0.1111/j.1365-2850.2004.00693.x.

Francis, R. 2013. "Report of the Mid Staffordshire NHS Foundation Trust Public Inquiry.” London: The Stationery Office.

Fraser, D. 2015. “Service User Involvement in an Occupational Therapy Curriculum.” Poster presented at College of Occupational Therapists $39^{\text {th }}$ Annual Conference, Brighton, June 30 - July 2. The British Journal of Occupational Therapy 78 (8_supplement): 122.

http://journals.sagepub.com.proxy.worc.ac.uk/toc/bjod/78/8_suppl

Gibbs, G. R. 2007. “Analyzing Qualitative Data.” London: Sage Publications

Glasby, J., and P. Beresford. 2006. "Who Knows Best? Evidence-Based Practice and the Service User Contribution.” Critical Social Policy 26 (1): 268-284. http://dx.doi.org/10.1177/0261018306059775.

Graham, A. T. 2015. “Academic Staff Performance and Workload in Higher Education in the UK: The Conceptual Dichotomy. Journal of Further and Higher Education 39 (5) 665-679. http://dx.doi.org/10.1080/0309877X.2014.971110

GSCC (General Social Care Council). 2005. "Working Towards Full Participation.” London: General Social Care Council.

Gutteridge, R., and K. Dobbins. 2010. "Service User and Carer Involvement in Learning and Teaching: A Faculty of Health Staff Perspective.” Nurse Education Today 30 (6): 509-514. http://dx.doi.org/10.1016/j.nedt.2009.10.019 
Happell, B., W. Bennetts, S. Harris, C. Plantaria-Phung, J. Tohatoa, L. Byre, and D. Wynaden. 2015. “Lived Experience in Teaching Mental Health Nursing: Issues of Fear and Power.” International Journal of Mental Health Nursing 24: 19 27. http://dx.doi.org/10.1111/inm.12091.

Harris, J. 2003. “The Social Work Business.” London: Routledge.

Harris, J., and P. Unwin. 2009. 'Performance Management in Modernised Social Work’. In Harris, J. and White, V. (eds) Modernising Social Work - Critical Considerations. Bristol: Policy Press.

Holttum, S., and M. Hayward. 2010. "Perceived Improvements in Service User Involvement in Two Clinical Psychology Courses.” Psychology Learning and Teaching 9: 16-24. doi: 10.2304/plat.2010.9.1.16

Ion, R., S. Cowan, and R. Lindsay. 2010. “Working with People who have been there: The Meaningful Involvement of Mental Health Service Users in Curriculum Design and Delivery.” Journal of Mental Health Training Education and Practice 5 (1): 4 - 10. http://dx.doi.org10.5042/jmtep.2010.0214

Lea, L., S. Holttum, A. Cooke, and L. Riley. 2016. “Aims for Service User Involvement in Mental Health Training: Staying Human.” Journal of Mental Health Training Education and Practice 11 (4): 208 - 219. http://dx.org/10.1108/JMHTEP-01$\underline{2016-0008}$

Mackey, R., and J. Millar. 2012. "Involving Service Users in the Classroom with Social Work Students.” Nurse Education Today 32: 167-172. http://dx.doi.org/10.1016/jnedt.2011.10.004.

Masters, H., S. Forrest, A. Harley, M. Hunter, N. Brown, and I. Risk. 2002. "Involving Service Users and Carers in Curriculum Development: Moving Beyond ‘Classroom' Involvement.” Journal of Psychiatric and Mental Health Nursing 9: 309 - 316. http://dx.doi.org/10.1046/j.1365-2850.2002.00493.x. 
Matka, E., D. River, R. Littlechild, and T. Powell. 2010. “Involving Service Users and Carers in Admissions for Courses in Social Work and Clinical Psychology: Cross-Disciplinary Comparison of Practices at the University of Birmingham.” British Journal of Social Work 40 (7): 2137-2154. https://doi.org/10.1093/bjsw/bcParticipant142.

McGarry, J., and N. Thom. 2004. "How Users and Carers View Their Involvement in Nurse Education.” Nursing Times 100 (18): 36-39. https://www.nursingtimes.net/roles/nurse-managers/how-users-and-carers-viewtheir-involvement-in-nurse-education/204361.article

Molyneaux, J., and J. Irvine. 2004. "Service User and Carer Involvement in Social Work Training: A Long and Winding Road?” Social Work Education 23 (3): 293-308. http://dx.doi/10.1080/0261547042000224047.

Naidoo, R., V. Shankar, and E. Veer. 2011. “The Consumerist Turn in Higher Education: Policy Aspirations and Outcomes.” Journal of Marketing Management 27: 1142-1162. http://dx.doi.org/10.1080/0267257X.2011.609135.

National Health Service and Community Care Act. 1990. London: The Stationery Office.

O’Keefe, M., and A. Jones. 2007. "Promoting Lay Participation in Medical School Curriculum Development: Lay and Faculty Perceptions.” Medical Education 41: 130 - 137. http://dx.doi.org/10.1111/j.1365-2929.2006.02666.x

Rhodes, C. A., and I. D. Nyawata. 2011. "Service User and Carer Involvement in Student Nurse Selection: Key Stakeholder Perspectives.” Nurse Education Today 31: 439 - 443. http://dx.doi.org/10.1016/j.nedt.2010.10.005.

Robson, C. (2011). “Real World Research.” Chichester: John Wiley \& Sons. 
Rooney, J. M., P. Unwin, and N. Osborne. 2016. “Gaining by Giving? Peer Research into Service User and Carer Perceptions of Inclusivity in Higher Education.” Social Work Education 35(8). 945-959. http://dx.doi.org/10.1080/02615479.2016.1227314.

Simons, L., S. Tee, J. Lathlean, A. Burgess, L. Herbert, and C. Gibson. 2007. “A Socially Inclusive Approach to User Participation in Higher Education.” Journal of Advanced Nursing 58: 246-255. http://dx.doi.org/10.1111/j.1365-2648.2007.04216.x.

Simons, L., S. Tee, and T. Coldham. 2010. “Developing Values-Based Education through Service User Participation.” The Journal of Mental Health Training, Education and Practice 5 (1): 20-27. http://dx.doi.org/10.5042/jmhetp.2010.0216.

Skilton, C. J. 2011. “Involving Experts by Experience in Assessing Students’ Readiness to Practice: The Value of Experiential Learning in Student Reflection and Preparation for Practice.” Social Work Education 30: 299-331. http://dx.doi.org/10.1080/02615479.2010.482982

Speed, S., J. Griffiths, M. Horne, and P. Keeley. 2012. “Pitfalls, Perils and Payments: Service User, Carers and Teaching Staff Perceptions of the Barriers to Involvement in Nursing Education.” Nurse Education Today. 32 (7): 829-834. http://dx.doi.org/10.1016/j.nedt.2012.04.013

Stacey, G., T. Stickley, and B. Rush. 2012. "Service User Involvement in the Assessment of Student Nurses: A Note of Caution.” Nurse Education Today 32 (5): 482- 484. http://dx.doi.org/10.1016/j.nedt.2011.12.001

Taylor, I., E. Sharland, J. Sebba, P. Leriche, E. Keep, and D. Orr. 2006. “The Learning, Teaching and Assessment of Partnership Work in Social Work Education.” Social Work Education Knowledge Review 10. London: Social Care Institute for Excellence. http://www.scie.org.uk/publications/knowledgereviews/kr10.asp 
Unwin, P., J. M. Rooney, and C. Cole. 2017. “An Evaluation of the Impact of Service User and Carer Involvement on Students’ Classroom Learning in Higher Education.” Journal of Further and Higher Education. http://dx.doi.org/10.1080/0309877X.2017.1281886.

Vandrevala, T., M. Hayward, J. Willis, and M. John. 2007. “A Move towards a Culture of Involvement: Involving Service Users and Carers in the Selection of Future Clinical Psychologists.” Journal of Mental Health Training, Education and Practice, 2(3): 34- 44. http://dx.doi.org/10.1108/17556228200700019.

Webber, M., and K. Robinson. 2012. ‘The Meaningful Involvement of Service Users and Carers in Advanced-Level Post-Qualifying Social Work Education: A Qualitative Study.” British Journal of Social Work 42 (7): 1256-1274. https://doi.org/10.1093/bjsw/bcr141 